\section{A POSIÇÃO DE QUINE ACERCA DA ANALITICIDADE KANTIANA E A SOLUÇÃO DE SEARLE PARA A OBSCURIDADE DO USO DO TERMO "ANALÍTICO"}

\section{Michelle Cardoso Montoya Graduanda Universidade Federal Fluminense}

Resumo: O presente artigo tem por objetivo expor de forma sucinta a noção de analiticidade proposta pelo filósofo alemão Immanuel Kant, para então apresentar de forma básica a crítica de Quine à leitura empirista acerca da noção de analiticidade. E então, a partir das apresentações da analiticidade em Kant e Quine, desenvolverei a argumentação de John Searle à favor do uso utilitário do conceito de "analítico" na Filosofia. Embora esse conceito seja falho, segundo Searle, ao contrário do que se poderia afirmar, nós poderíamos fazer um bom uso dele, desde que utilizássemos seus critérios adequadamente. Sendo assim, serão desenvolvidos os argumentos de Searle presentes em sua obra Speech Acts a favor de um novo uso utilitário do termo "analítico" para a Filosofia. Com isso, conseguiremos expor um posicionamento favorável acerca da analiticidade kantiana pré-dita antes como obscura.

Palavras chave: Analiticidade; Positivismo lógico; Semântica.

\begin{abstract}
The present article intend expose succintly the notion of analycity that proposed by German philosopher Imannuel Kant, for then to introduce of basic form the criticism of Quine the empiricism reading about the notion of analycity. And then, from these exhibts of analycity in Kant and Quine, I will develop the argument of John Searle in favor of utilitary use of "analytical" term in Philosophy.Although that concept be defective, in according Searle, contrary to what can be affirm, we could to do a great use it, since we used your canons adequaly. Thus, will developed the arguments of Searle presents in his work Speech Acts in favor of a new utilitary use of "analytical" term for Philosophy. Thereat, we will be get to expose a favorable position about Kantian's analycity predicted before like obscure.
\end{abstract}

Keywords: Analycity; Logic Positivism; Semantic.

\section{INTRODUÇÃO}

O problema da analiticidade tem sido objeto de discussão entre vários autores célebres, desde o fim da modernidade até os dias atuais, tais como Frege, Carnap e o círculo vienense, Quine, Strawson, Grice, Tarski, Putnam,Searle, Morton White e dentre outros.

Kant, ao estabelecer sua célebre distinção entre juízos analíticos e sintéticos no século XVIII, numa tentativa de solucionar os problemas propostos pela Crítica da Razão Pura e a fim de assegurar positivamente uma possibilidade de se fazer uma Metafísica ou não, propõe o emprego de fundamentos lógicos para tal feito, tais como os que estão imbuídos originariamente na analiticidade (princípio da não-contradição, tautologia,e entre outros).

Contudo, segundo alguns interlocutores como Quine e o círculo vienense, Kant teria definido obscuramente as diretrizes do tema da analiticidade e circunscrito sua definição em trilhas muito obscuras. Esse fato, segundo eles, teria se dado por conta de aspectos de obviedade. Kant não teria utilizado "clareza" justamente porque o tema seria óbvio, seria dado. Primeiramente porque o texto de Kant não se destinaria aos que estavam fora da discussão que ele estava propondo. Segundo, Kant escreveu a Crítica pressupondo que muitos dos seus leitores já entendessem minimamente não só a sua discussão, mas também deveriam entender sobre qual discussão a tradição entravava há muito tempo, acerca da Metafísica. Em terceiro lugar, para o círculo vienense, Kant, ao tentar fundamentar algum tipo de Metafísica em última instância, teria inaugurado não só uma possibilidade de leitura da analiticidade em termos lógicos, mas também em termos semânticos.

Willard Van Orman Quine, fortemente influenciado pelas ideias do positivismo lógico do Círculo de Viena (também conhecido como empirismo lógico), teria sido apresentado 
possivelmente ao tema da analiticidade por esse círculo filosófico, e a muitos outros temas acerca dos quais o positivismo lógico tratava, tais como o problema da verdade científica, a teoria da confirmação e o verificacionismo .Quine teria tido contato com o Círculo de Viena fortemente, e por meio deste, teria conhecido a distinção clássica acerca da analiticidade. Ainda há quem diga que ele sequer teria lido Kant, tendo então adquirido então um conhecimento acerca da analiticidade cunhado por esse círculo filosófico. Logo, Quine talvez só conheceria tal tema perifericamente.

Quine teria conhecido o problema da analiticidade nos cursos de Moritz Schlick, com uma abordagem interpretativa semanticizada proposta pelo Círculo de Viena. Por isso , em seus artigos, constantemente Quine estaria estabelecendo debates e diálogos com interlocutores do Círculo do Viena. Um exemplo disso seria quando Quine em "Two Dogmas of Empiricism" trava uma discussão com Rudolph Carnap, que inclusive resultará em uma resposta sagaz dada por Carnap em "Meaning and Synonymy in Natural Languages" (1955), artigo em que ele discute as noções de analiticidade e necessidade, ora encaminhando-as para a Lógica, ora encaminhando-as para a Semântica.

Segundo John Searle, frequentemente criticariase que nos falta um análise adequada do conceito de analiticidade, e que consequentemente nos faltariam critérios para decidir se um enunciado é analítico ou não. Contudo, o nosso fracasso não residiria em encontrar critérios para esses juízos, mas sim em não admitir que sabemos o que a analiticidade significa, logo sabemos quais tipos de considerações influenciariam na decisão de caracterizar um enunciado como analítico ou não.
Primeiramente, o critério para a analiticidade deveria ser julgado em função dos resultados que este permite obter. Em segundo lugar, a capacidade de uma pessoa continuar a listar exemplos de enunciados analíticos seria equivalente a compreensão do termo "analítico". A isto, Searle irá chamar de capacidade projetiva. Logo, a analiticidade teria natureza projetiva, isto é, "analítico" não representaria uma classe fechada de enunciados, mas sim uma classe de enunciados aberta e com possibilidades de projeção. Em outras palavras, nós sempre saberemos, segundo ele, aplicar a analiticidade a todos os termos e enunciados que surgirem. Até mesmo em certos casos limite, seríamos plenamente capazes de reconhecer o conceito desde que o dominássemos no âmbito de competência linguística. Só reconheceríamos os próprios limites do conceito o apreendendo. $\mathrm{O}$ caso limite citado por Quine ("Tudo que é verde tem extensão") é um exemplo de um caso em que não conseguimos ter certeza quanto a analiticidade ou não do enunciado. Contudo, isso se daria justamente pelo único fato de que sabemos aplicar o conceito de analítico segundo Searle.

Vemos então que, para Searle, seria um erro terminológico afirmar que a analiticidade é obscura, pois se assim fosse, como saberíamos que "analítico" é um termo obscuro? Ora, sabemos disso porque sabemos significar e definir esse termo. Se fosse o contrário disso, sequer poderíamos algum dia dizer ou desdizer qualquer coisa a respeito da analiticidade. "Analítico", tal como preconizou Grice, já seria um termo pertencente a uma classe de enunciados aberta, contudo com caráter holístico Porém, Searle ainda diz mais: o caráter holístico da analiticidade se dá justamente porque sabemos o que ela significa, caso contrário, como conseguiríamos garantir 
alguma circularidade de termos sem saber o significado dos mesmos?

Para Searle, diferentemente do que se preconizava até então, acreditava que a analiticidade não era obscura, que Kant nunca quis obscurecê-la. Pelo contrário, ela é tão óbvia que todos tentariam obscurecê-la.

Tal como Ian Proops afirmou em seu artigo "Kan'ts Conception of Analytic Judgment", poucas ideias obtiveram um impacto tão grande na Filosofia Analítica do que a célebre distinção entre juízos analíticos e sintéticos, e apesar de ser uma distinção importante, vários debates acerca de sua coerência foram travados. Sendo assim, nos questionaríamos: "Será que essa distinção tão célebre é na verdade obscura?", ou "Será que ao interpretarmos essa distinção estaríamos seguindo os cânones errados?".

O presente artigo seguirá seu curso encaminhandose pelo viés da segunda questão proposta ao nos questionarmos. Por meio da solução otimista de Searle para a discussão acerca da analiticidade kantiana perceberemos que Kant não obscureceu suas definições e critérios acerca da analiticidade, isto é, não obscureceu critérios acerca do modo pelo qual devemos considerar um juízo como analítico ou sintético. Ainda, poderemos observar também que ao analisarmos críticas como as de Quine acerca da concepção de analiticidade kantiana dos empiristas lógicos (ou positivistas lógicos) ampliaremos o nosso horizonte interpretativo acerca da analiticidade, para então podermos lapidar um critério que possa ser utilitário para a Filosofia: os juízos analíticos.

\section{A C ONCEPÇÃO KANTIANA DE ANALITICIDADE}

Embora outros autores como Leibniz ou Hume já tivessem tratado de temas semelhantes ao conceito de analiticidade em Kant. Leibniz em sua obra Novos Ensaios Sobre o Entendimento Humano, cria a distinção entre "verdades da razão" e "verdades de fato", termos que segundo alguns debatedores acerca do tema da analiticidade (como Quine em "Two Dogmas of Empiricism") já seriam um prelúdio à analiticidade, isto é, os termos de Leibniz, na verdade, queriam dizer o mesmo discurso que Kant defenderá posteriormente na Crítica. As verdades da razão em Leibniz assumiriam o mesmo estatuto que os juízos analíticos kantianos, pois, elas seriam necessárias e universais. Verdades da razão em Leibniz só se diferenciariam dos juízos analíticos em Kant quanto à sua origem, enquanto as verdades de fato dependeriam de contingências materiais, enquanto as verdades da razão estariam a salvo de modificações empíricas.

Quanto a Hume, vemos que seu plano de ideias e percepções também já anunciaria o mesmo prelúdio feito por Leibniz .Inclusive, na Crítica, Kant irá criticar a noção de causalidade em Hume, uma vez que esta se sustentaria no hábito, que nos daria uma aparência de necessidade quanto ao princípio de todas as coisas. A distinção clássica entre juízos analíticos e sintéticos teria se dado oficialmente na Crítica da Razão Pura, com Kant, tal como podemos ver abaixo:

Em todos os juízos, nos quais se pensa a relação entre um sujeito e um predicado (apenas considero os juízos afirmativos, porque é fácil depois a aplicação aos negativos), esta relação é possível de dois modos. Ou o predicado B pertence ao sujeito A como algo que está contido (implicitamente) nesse conceito A, ou B está totalmente fora do conceito A, 
embora em ligação com ele. No primeiro caso chamo analítico ao juízo, no segundo, sintético.”(KrV B16)

Nesse momento, na parte IV da Introdução da Crítica, Kant define o que se pode entender basicamente por juízos analíticos e sintéticos. Vemos nessa passagem que, segundo Kant, um juízo analítico seria aquele em que um predicado já está contido implicitamente em um sujeito. Primariamente, o predicado que podemos associar imediatamente ao sujeito A, é apenas uma explicação do juízo que foi exposto, sem que qualquer coisa tenha sido acrescentada a ele. Um exemplo que Kant utilizou para ilustrar juízos analíticos foi : "Todo corpo é extenso" (KrV B20.) .Segundo Kant, ao decompor o conceito de extensão explicitado nesse enunciado, não preciso ultrapassá-lo, isto é, bastaria que eu refletisse a respeito desse conceito para entendê-lo. Imediatamente, ligaria o conceito de corpo ao conceito de extensão .Ou seja, não se compreenderia o que é corpo sem compreender o predicado "extensão", logo, compreender "corpo" significa compreender o que é "extensão". Com isso, eu não precisaria recorrer à experiência para compreender tal conceito que é meramente um adendo explicativo para o termo "corpo".

Um juízo sintético para Kant teria um caráter extensivo de conhecimento. Por exemplo, se digo "Todos os corpos são leves", vemos que o predicado "leve" não está incluso numa ligação imediata entre conceito e sujeito, ou seja, eu preciso buscar fora do sujeito algo que me faça ligar este predicado "leve" a um conceito imediato de "corpo". Eu precisaria recorrer à algo externo ao sujeito em questão para encontrar esse conceito. Se eu não posso ligar imediatamente o conceito de "leve" ao sujeito "corpo" por meio de uma breve reflexão, terei de recorrer por exemplo a experiência, para que a mesma me ofereça elementos que auxiliem-me com tal ligação. Por isso, que para Kant, todos os juízos de experiência serão sintéticos (KrV B12).

Segundo Kant, a compreensão de que um corpo é extenso adviria de uma compreensão à priori de "corpo", isto é, independe-se da experiência para compreender a aplicação do conceito de extensão neste caso. Nesse caso a definição do objeto corresponderia identicamente a do sujeito. Deve-se ressaltar neste ponto que o próprio exemplo dado por Kant acerca da concepção de um juízo analítico é em si mesmo problemático. "Afinal, será mesmo que a associação que podemos fazer entre o sujeito 'corpo' e o predicado extensão seria tão óbvia e imediata assim?" Vemos então que é bastante discutível essa associação imediata. Talvez alguns mais céticos dirão que sequer há extensão, e tampouco que a mesma se dá num determinado espaço. Mediante ao exemplo kantiano de que "todo corpo tem extensão", podemos perceber o quanto os critérios de analiticidade podem se tornar discutíveis e problemáticos.

Sendo assim, feita a apresentação básica da distinção entre juízos analíticos e sintéticos, quero ainda chamar a atenção do leitor sobre quatro principais características dadas a um juízo analítico, uma vez que compreendê-las se constituirá num elemento fundamental para se compreender as bases que estruturam o problema da analiticidade. Ian Proops em "Kant's conception analytics" (2005), propõe fundamentadamente a existência dessas quatro características presentes na concepção kantiana de juízos analíticos, e, por concordância, as utilizarei para abordar certos aspectos que creio 
não terem sido suficientemente esclarecidos num primeiro momento.

Primeiramente, deve-se comentar que a primeira característica de um juízo analítico é a sua limitação, isto é, seu aspecto restritivo. Digo restritivo por três razões principais. A primeira delas se dá ao fato desses juízos também serem nomeados como "elucidativos", ou seja, significa que eles teriam o objetivo único e fim último de esclarecer alguma informação acerca da definição de um sujeito dado. Ou seja, um juízo analítico se restringe apenas a dar esclarecimentos acerca da definição de um determinado sujeito em questão.A segunda razão se deve ao fato de um juízo analítico não poder ser considerado como tal caso se funde na experiência. Ou seja, se já possuo em meu juízo um conceito de um determinado sujeito, sem precisar de algum testemunho da experiência, seria absurdo que eu fundasse um juízo analítico com base na experiência .A terceira e última razão que nos permitiria reconhecer esse aspecto restritivo seria a de que se todo juízo analítico é a priori, isto é, independe do conhecimento, e um juízo a priori é tido como universal e necessário, logo um juízo analítico é universal e necessário. Ou seja, um juízo analítico possui o aspecto restritivo de necessidade e universalidade. A partir disso, perceber-se-á que um juízo analítico será fundamental na constituição das bases da Lógica para Kant, uma vez que em suas modalidades lógicas teremos critérios de juízos universais e necessários.

Kant, na em sua Analítica Transcedental nos mostrará uma tábula sobre o entendimento decomposto em juízos em termos de qualidade, quantidade, modalidade e relação. ( $\mathrm{KrV}, \S 9$, B95). A modalidade seria uma das funções lógicas do pensamento que encerraria o processo do entendimento. Já a universalidade, diria respeito a quantidade dos juízos, isto é, ao que costumeiramente titulamos como extensão. Uma boa definição de extensão neste caso seria a dada por Quine em "Two Dogmas of Empiricism": "A classe de todas as entidades das quais um termo geral é verdadeiro é chamada extensão do termo"( QUINE,1951) .

A segunda característica de um juízo analítico se daria em termos de identidade. Ou seja, quando falamos que uma das características de um juízo analítico se dá em termos de identidade, queremos nos referir a tautologia " $a=a$ ".Aqui verificamos que a analiticidade nos dá um estatuto de verificabilidade lógica para juízos. Por meio da tautologia podemos estar em contato com a genuína definição de analiticidade. Por meio dessa tautologia, a analiticidade poderá ter um estatuto de verdade lógica. Esse estatuto será importante para compreendermos adiante a divisão que Quine irá fazer sobre a analiticidade, dividindo juízos analíticos em duas classes, sendo elas: juízos analíticos logicamente verdadeiros e juízos analíticos substitutivos (QUINE, 1951).

A terceira característica se referiria a alusão do contraste explicativo-ampliativo, que embora não seja facilmente percebida, podemos induzíla do seguinte modo: se um juízo analítico "explica" a definição de um dado sujeito, logo ele predicará o sujeito com um predicado que não é estritamente exclusivo em termos de aplicabilidade a esse sujeito. Ou seja, ao caracterizarmos um sujeito por meio de um juízo analítico temos de lidar com a circularidade predicativa, isto é, ao eu aplicar um predicado a um sujeito, sei que ele não é aplicável unicamente a esse sujeito. Logo, pressupõe-se que há um conjunto de outros predicados que podem predicar o predicado que eu estou aplicando a esse sujeito, criando 
assim uma circularidade predicativa, que em até certo ponto podemos nomear de círculo de intensões familiares no sentido de Strawson e Grice.Strawson irá comentar a respeito dessa circularidade em "The Bounds of Sense: An Essay on Kant's Critique of Pure Reason" (1966), bem como em um artigo que redigiu em conjunto com Grice, “Defense of a Dogma” (1956).

A quarta característica de um juízo analítico, dirá respeito a "cognicibilidade em conformidade com o princípio da contradição", que se trata também de um princípio de Lógica Elementar, ou seja, uma tautologia pode "ser cognoscível" desde que não se contraponha ao princípio de nãocontradição.

Podemos perceber então, que na verdade, diferentemente do que autores como Quine, Strawson e Grice interpretavam, Kant não defendia uma analiticidade semântica, mas sim uma analiticidade lógica, pois pelas caracterizações que já citamos, já está claro que Kant pretendia preservar a necessidade lógica e outros princípios a ela atrelados por meio da definição de analiticidade.

\section{A CONCEPÇÃO DE ANALITICIDADE EM QUINE}

Quine, em seu artigo Two Dogmas of Empiricism (1951), defende uma interpretação semântica acerca do conceito de analiticidade. Em Word and Object também irá trabalhar com a noção de estímulo analítico, classificando assim, behavioristicamente a analiticidade em um aspecto semântico ligado a uma expressão comportamental. Segundo ele, quando Kant afirmara que um enunciado analítico atribuía ao sujeito um predicado que já estava contido no sujeito, na verdade, Kant queria dizer que "um enunciado é analítico quando verdadeiro em virtude de significados e independente de fatos" (QUINE,1951). Percebe-se assim, que para Quine, quando Kant caracterizou um juízo analítico, ele na verdade teria criado uma analiticidade semântica e não lógica, embora essa fosse sua intenção.

Veremos que Quine, no artigo supracitado demonstrará que qualquer enunciado poderá ser revisado, tendo seu valor de verdade alterado. E essa revisão de enunciado, se estenderia também à Lógica, embora com um certo grau de resistência. Ele irá apontar no mesmo artigo, cerca de sete problemas insolúveis desencadeados pela analiticidade preconizada pelo empirismo lógico. Sendo eles: a distinção entre juízos analíticos e sintéticos, o caráter holístico da analiticidade, a contradição lógica embutida na analiticidade, o critério de verdade lógica, o problema da sinonímia, o problema dos mundos possíveis (no sentido de descrições de estado carnapianas) e impossibilidade de explicitação da analiticidade em termos de definição, aplicando para este último um Paradoxo da Análise, tal como o fez semelhantemente Moore. E por meio dos problemas que ressalta, faz analisa três vias falhas de salvaguardar a analiticidade como algo em si, isto é, autossuficiente e autônoma ontologicamente, sendo elas a da sinonímia e significado, a da definição e a das regras semânticas.

Quine, nesse artigo supracitado, primeiramente, divide os juízos analíticos em duas classes: em logicamente verdadeiros e numa segunda classe que ele não nomeia, e devido a sua operacionalidade, os chamarei de substitutivos. A característica do primeiro tipo de juízos analíticos seria a de que eles sempre permaneceriam verdadeiros sob todas as interpretações de seus componentes, exceto de suas partículas lógicas (QUINE,1951). 
Já no caso dos juízos analíticos substitutivos, um enunciado poderia ser transformado em verdade lógica por meio da substituição de sinônimos. Por exemplo, eu poderia substituir o termo "solteiro" pelos termos "homem não casado".Contudo essa segunda classe de juízos analíticos seria problemática segundo Quine, pois, o conceito de sinonímia seria ainda mais obscuro que o de analiticidade. A primeira classe de juízos analíticos, para Quine, também apresentaria problemas, pois se valeria de critérios de verdades lógicas, critérios esses que são totalmente distintos do que se esperaria dos de analiticidade.

Nesse ponto, Quine ainda criticará Carnap por associar o problema da analiticidade a meras descrições de estado, que na verdade só teriam critérios disponíveis para verdades lógicas e não para a analiticidade. Para Quine, ela seria menos que uma verdade lógica e teria um estatuto semântico.

Quine dirá neste ponto que também haveriam sérios equívocos quanto a noção de significado. Citando exemplos de Russell, dirá que "Scott" na verdade seria totalmente distinto de "O autor de Waverley".Aqui haveria uma confusão acerca da noção de significado. Ambos exemplos de Russell serviriam para nomear uma mesma entidade, a saber, Scott. Todavia, nomear constituiria tão somente dar nome a um objeto, enquanto significar diria respeito a ideias que temos na mente acerca de tal objeto. Tais ideias seriam impressas em nossa mente por meio do comportamento linguístico dos falantes a nossa volta, uma vez que linguagem seria uma arte social que todos nós adquirimos (QUINE,1960).

A distinção entre nomear e significar se sustentaria também a partir do critério de extensão sentencial observável4. Nos casos de termos gerais, vemos que eles são verdadeiros de uma ou muitas entidades, logo seriam atribuídos a classes de entidades que tornariam possível tal distinção por meio de significados distintos que costumam lhe ser atribuídas. Do mesmo modo, a noção de essência aristotélica teria sido precursora da noção de intenção e significado, embora, de acordo com Quine, só servisse para falar de coisas e não das formas linguísticas tal como o significado deveria se propor originariamente.

No segundo momento do referido artigo, Quine critica a tentativa de esclarecer o conceito de analiticidade em termos de definição. Segundo ele, ao fazermos isso, ao decompormos os termos de um enunciado (definiens e definiendum), decaímos novamente no problema da sinonímia dos termos, elemento que conforme dito anteriormente, é ainda mais obscuro que o próprio conceito de analiticidade. Conceituar a analiticidade em termos de analiticidade neste caso, não só nos encaminharia para um conceito ainda mais obscuro. Nos encaminharia para uma circularidade predicativa, isto é,a uma circularidade familiar intensional ou holismo semântico.

Outra crítica de Quine se dará a partir da permutabilidade de termos linguísticos, ou melhor dizendo, quanto a uma suposta sinonímia cognitiva, onde segundo ele , apesar de se valer de uma permutabilidade do tipo salva veritate, ainda não apresentaria condições suficientes de clareza, embora seja um tipo de sinonímia mais rigorosa.

No fim desse artigo, Quine comenta que após suas demonstrações acerca da falibilidade das tentativas de se definir o conceito de analítico, nota-se que na verdade, juízos analíticos e sintéticos não poderiam ser analisados separadamente, ou seja, não poderiam ser decompostos, uma vez que as proposições e enunciados são variáveis ao longo do tempo. Muito do que se é pronunciado seria revisto ao 
longo do tempo. Sendo assim, esses juízos deveriam ser interdependentes e jamais decompostos a fim de se analisá-los separadamente.

Contudo, ao longo de sua obra, Quine tardiamente, embora mantivesse seu posicionamento quanto a leitura semântica da analiticidade, muda seu forma de abordá-la em sua obra posterior Word and Object, criando a noção de estímulo analítico (stimulos analysis), que será ainda mais problemática: "Eu chamo de estímulo analítico aquele em que o sujeito assente afirmativamente ou não, em todo estímulo dado por um mesmo módulo"(QUINE, 1960).

\section{A SOLUÇÃO OTIMISTA DE SEARLE PARA O USO DO TERMO “ANALÍTICO”}

Segundo Searle, frequentemente critica-se que nos falta um análise adequada do conceito de analiticidade, e que consequentemente nos faltariam critérios para decidir se um enunciado é analítico ou não. Contudo, o nosso fracasso não residiria em encontrar critérios para esses juízos, mas sim em não admitir que sabemos o que a analiticidade significa, logo sabemos quais tipos de considerações influenciariam na decisão de caracterizar um enunciado como analítico ou não.

O critério de analiticidade deveria ser julgado em função dos resultados que ele permite se obter. Ou seja, por meio da capacidade projetiva, poderíamos obter julgamentos analíticos, uma vez que a analiticidade seria de natureza projetiva. Esta capacidade, se daria porque nós conseguimos dominar o conceito de analítico. Por meio deste domínio, conseguiríamos aplicar encadeadamente o conceito de analiticidade a qualquer enunciado. Searle propõe que certos problemas relacionados a elementos relativos a caracterizações linguísticas poderiam ser solucionados por meio desta capacidade, dentre eles, o da sinonímia.

Não faltaria critérios para a analiticidade, pois a definição que normalmente damos a ela já nos oferece uma espécie de critério: “ (...) a analiticidade é, por sua vez, assim definida: um enunciado é analítico, se e somente se, for verdadeiro em virtude da significação ou por definição" (SEARLE, 1977). Sendo assim, teríamos critérios de definição totalmente claros sobre o que seria a analiticidade. Se ilustrássemos um pouco mais todos os critérios os quais nos dirigimos com essa definição, qualquer um a compreenderá, vemos então a eficiência dela. Contudo, precisaremos apenas ilustrá-la mediante a alguns exemplos.Contudo, no caso da significação, ainda teríamos um certo grau de obscuridade, que para Searle, se apagaria mediante a busca de critérios extensionais, behavioristas e/ou formais.

Logo, a ausência de um teste objetivo para a analiticidade tornaria seus conceitos defeituosos e não o contrário, tal como veremos a seguir. Objeções acerca de certas noções repousariam sobre certas asserções gerais erradas quanto às relações entre nossa capacidade de fornecer critérios para essas noções para algum tipo de aplicação e a nossa compreensão delas. Então, Searle tenta por exemplo, tomar um critério que atenda às exigências já expostas, verificando se ele é adequado: “(...) um enunciado é analítico, se e somente se, a primeira palavra na frase usada para fazer este enunciado começar pela letra A" (SEARLE, 1977).

Certamente esse critério seria desejado por certos objetores, contudo, vemos claramente que ele seria insuficiente para dar conta do 
plano extensional. No entanto, de onde adviria o nosso conhecimento de que de fato esse critério é inadequado para ela? Como sabemos que as razões dadas para o problema da definição são relevantes?Segundo Searle, saberíamos disso justamente porque sabemos “o que analítico significa".Não saberíamos responder a tais perguntas e sequer teríamos a capacidade de formulá-las se não soubéssemos o que analítico significa. Estes conhecimentos sobre os critérios de analiticidade pressuporiam o conhecimento do que a palavra "analítico" significa. Logo, para Searle, sabemos perfeitamente quais tipos de consideração influenciam na decisão de caracterizar um enunciado como analítico ou não.

Sendo assim, nem sempre todo e qualquer critério extensional, formal ou behavorista atenderia as exigências necessárias ao se julgar enunciados de um modo em geral, isto é, esses critérios embora não pareçam, estão todos sujeitos a serem falíveis. O nosso fracasso em encontrar critérios do tipo proposto nos mostrariam justamente que compreendemos perfeitamente tal conceito de analiticidade, diferentemente do que alguns críticos costumavam a afirmar:"Não poderíamos prosseguir na nossa investigação se não compreendêssemos este conceito, pois é unicamente em virtude desta compreensão que poderemos avaliar a adequação dos critérios propostos" (SEARLE, 1977).

Primeiramente, o critério para a analiticidade deve ser julgado em função dos resultados que permite obter. Em segundo lugar, a capacidade de uma pessoa continuar a listar exemplos de enunciados analíticos seria equivalente a compreensão do termo "analítico".A isto, Searle irá chamar de capacidade projetiva. Logo, a analiticidade teria natureza projetiva, isto é, "analítico" não representaria uma classe fechada de enunciados, mas sim uma classe de enunciados aberta e com possibilidades de projeção. Em outras palavras, nós sempre saberemos segundo ele, aplicar a analiticidade a todos os termos e enunciados que surgirem. Até mesmo em certos casos limite, seríamos plenamente capazes de reconhecer o conceito desde que o dominássemos. Só reconheceríamos os próprios limites do conceito também o apreendendo. No caso limite citado por Quine por exemplo ("Tudo que é verde tem extensão") é um exemplo de um caso em que não conseguimos ter certeza quanto a analiticidade ou não do enunciado. Contudo, isso se daria justamente pelo único fato de que sabemos aplicar o conceito de analítico (SEARLE, 1977).

Vemos então, que para Searle seria um erro terminológico afirmar que a analiticidade é obscura, pois se assim fosse, como saberíamos que "analítico" é um termo obscuro?Ora, sabemos disso porque sabemos significar e definir esse termo. Se fosse o contrário disso, sequer poderíamos algum dia dizer ou desdizer qualquer coisa a respeito da analiticidade. "Analítico", tal como preconizou Grice, já seria um termo pertencente a uma classe de enunciados aberta, contudo com caráter holístico Porém, Searle ainda diz mais: o caráter holístico da analiticidade se dá justamente porque sabemos o que ela significa, caso contrário, como conseguiríamos garantir alguma circularidade de termos sem saber o significado dos mesmos. Para Searle, diferentemente do que se preconizava até então, acreditava que a analiticidade não era obscura, que Kant nunca quis obscurecê-la. Pelo contrário, ela é tão óbvia que todos tentariam obscurecê-la. 


\section{CONCLUSÕES E CONSIDERAÇÕES FINAIS}

Tal como Ian Proops afirmou em seu artigo "Kan'ts Conception of Analytic Judgment", poucas ideias obtiveram um impacto tão grande na Filosofia Analítica do que a célebre distinção entre juízos analíticos e sintéticos, e apesar de ser uma distinção importante, vários debates acerca de sua coerência foram travados. Sendo assim, nos questionaríamos: "Será que essa distinção tão célebre está , é na verdade obscura?", ou "Será que ao interpretarmos essa distinção estamos seguindo os cânones errados?".Este projeto seguirá seu curso encaminhando-se pelo viés da segunda questão proposta ao nos questionarmos.

Iremos perceber que Kant não obscurece suas definições e critérios acerca da analiticidade, isto é, não obscurece critérios acerca do modo pelo qual devemos considerar um juízo como analítico ou sintético. Ainda, poderemos observar que ao analisarmos críticas como as de Quine acerca da concepção de analiticidade dos empiristas lógicos (ou positivistas lógicos), ampliaremos o nosso horizonte interpretativo acerca da analiticidade, para então podermos lapidar um critério que possa ser utilitário para a Filosofia: os juízos analíticos.

Perceberemos que Searle dará um tom otimista a essa discussão, propondo uma solução alternativa para a mesma:“ E se nós admitirmos a falibilidade dessa definição e utilizarmos o conceito de "analítico" aceitando como falível?"Se ao invés de criarmos novos problemas acerca da definição de analiticidade, aceitando-a como falível tal como ela é, poderemos então fazer um uso filosófico utilitário da mesma. Sendo assim, creio que seja ideal levarmos em conta a discussão acerca da analiticidade trazendo algo para acrescentar-lhe. Em termos kantianos, seria adequado acrescentarmos uma crítica a essa discussão acerca da analiticidade, ou seja a abertura de condições de possibilidades para conduzirmos esse debate, embora essa abertura possa gerar uma tensão permanente ainda mais intensa. Contudo, creio que nos arriscarmos abrindo novas condições de possibilidades acerca do modo sobre o qual nos debruçamos sobre o tema pode ser bastante interessante. "Então, que tal reconhecermos a falibilidade da definição de analiticidade, admitindo os canônes que já possuímos a respeito da mesma e a utilizarmos dentro das limitações que a mesma possui?"

Se assim fizermos, poderemos nos despir de certos problemas desencadeados pela obscuridade da definição de "analítico", para que assim possamos nos tornar um pouco mais econômicos filosoficamente, isto é, poderemos apagar certos problemas gerados pela obscuridade já citada, tais como : "Um juízo pode ser analítico e sintético simultaneamente" ou "Todo juízo é sintético, uma vez que todo juízo analítico está contido num juízo sintético", são apenas alguns dos exemplos de interpretações possíveis equivocadas acerca da analiticidade.

Sendo assim, embora essa discussão perdure desde o fim da modernidade, vemos que ela continua sendo atual, uma vez que até os dias de hoje , debates acerca dela continuam sendo travados. Por isso, ainda é relevante abordarmos essa discussão, só que em um viés diferenciado, pois assim poderemos trazer um novo material discutível para a alimentarmos, na tentativa de solucioná-la, dando fim a um "pseudoproblema",embora essa abertura possa gerar uma tensão permanente ainda mais intensa. 
Nisto, vimos que Searle implicitamente segregou a relação entre juízos analíticos e sintéticos, sustentando novamente um posicionamento empirista acerca da analiticidade por meio de uma argumentação a favor de que já temos em nós mesmos critérios para definir a analiticidade. Sendo assim, apenas que precisaríamos aprender a utilizar as ferramentas filosóficas que a analiticidade poderá nos proporcionar apesar dela aparentar um caráter falibilista, reconhecendo todavia, que tal caráter é necessário para que a mesma seja autossuficiente ontologicamente.

\section{Referencias Bibliográficas}

BENNETT, Jonathan. Kants Analytic. New York: Cambridge University Press, 1992.

CARNAP, Rudolph; Schlick, Moritz.Coletânea de textos.São Paulo: Nova Cultural, 1988.

GIBSON, ROGER F. (organizador). The Cambridge Companion to Quine. New York: Cambridge University Press, 2004.

GRICE, Herbert Paul;Strawson, Peter Frederick. In Defense of a Dogma. The Philosophical Review, Durhem, volume. 65, número 2, 1956 .pp. 141-158.

KANT, Immanuel .Crítica da Razão Pura .São Paulo: Nova Cultural, 1991.

KANT, Immanuel. Crítica da Razão Pura .Rio de Janeiro: Vozes, 2012.

KANT, Immanuel. Crítica da Razão Pura. $7^{\mathrm{a}}$ edição. Lisboa: Fundação Calouste Gulbenkian, 2010.

KANT, Immanuel. Kritik der reinen Vernunft. $2^{a}$ edição.London: Macmillan, 1929.

KANT, Immanuel.Lógica.Rio de Janeiro: Tempo Brasileiro, 1992.

KANT, Immanuel.Manual dos cursos de lógica geral.Campinas: IFCH-UNICAMP, 1998.

PROOPS, Ian . Kant's Conception of analytic judgment.Philosophy and Phenomenological Research, United Kingdom,volume 70, $3^{\mathrm{a} e d i c ̧ a ̃ o, 2005 . p p . ~}$ 588-612.

QUINE, Willard Van Orman .The roots of reference. La Salle, Illinois: Open Court Publishing Co., 1974. 
QUINE, Willard Van Orman (1960).Word and Object . Cambridge, Mass.: MIT Press, 2015 .

QUINE, Willard Van Orman. From a Logical Point of View. $2^{\text {a }}$ edição.Cambridge/Harvard Press, 2003.

QUINE,Willard Van Orman (1951). "Dois dogmas do empirismo"In: Relatividade ontológica e outros ensaios (col.Os Pensadores) $2^{\mathrm{a}}$ edição. São Paulo: Abril Cultural, 1980.

QUINE,Willard Van Orman. Pursuit of truth. Cambridge, Massaschusetts: Harvard University Press, 1990.

SEARLE, John R . Speech acts: an essay in the philosophy of language. London : Cambridge University Press, 1977.

SEARLE,John R. (1977). Os actos de fala Um ensaio de Filosofia da Linguagem.Coimbra: Livraria Almedina, 1984.

STRAWSON, Peter Frederick. An Essay on Kant's Critique of Pure Reason . London: Methuen \& Co. Ltd., 1966. 